\title{
On $B^{*} \mathrm{c}-$ open set and its properties
}

Raad Aziz Hussan Al - Abdulla

Department of Mathematics

College computer science and Information Technology

AL- Qadisiyah university

DOI: 10.29304/jqcm.2019.11.1.447

\begin{abstract}
:
In this paper we introduced a new set is said $\mathrm{B}^{*} \mathrm{c}-$ open set where we studied and identified its properties and find the relation with other sets and our concluded a new class of the function called $\mathrm{B}^{*} \mathrm{c}-$ cont. function, $\mathrm{B}^{*} \mathrm{c}-$ open function, $\mathrm{B}^{*} \mathrm{c}-$ closed function.
\end{abstract}

Key words:

$\mathrm{B}^{*} \mathrm{c}-$ open set, $\mathrm{B}^{*} \mathrm{c}-$ closed set, $\mathrm{B}^{*} \mathrm{c}-$ closure, $\mathrm{B}^{*} \mathrm{c}-$ interior, $\mathrm{B}^{*} \mathrm{c}-$ continuous.

Mathematics subject classification: $\mathbf{5 4 x x}$. 


\section{Raad .A/Karim .F}

\section{1- Introduction :}

The topological idea from study this set is generalization the properties and using its to prove many of the theorems. In [1]Abd El-Monsef M.E.,El.Deeb S.N. Mahmoud R.A Introduced set of class $\beta$ - open, $\beta$ - closed which are considered as in put to study the set of class $\mathrm{B}^{*} \mathrm{c}-$ open, $\mathrm{B}^{*} \mathrm{c}$ - closed and we introduced the interior and the closure as property of $\mathrm{B}^{*} \mathrm{c}-$ open set, $\mathrm{B}^{*} \mathrm{c}-$ closed set. In [4] Najasted O (1965) and [5] Andrijecivic D (1986) introduced a study about the set $\alpha$-open, $\alpha$-closed, B - open with the set $\beta$ - open set and through it, we introduced proof many of proposition as the set $\mathrm{B}^{*} \mathrm{c}$ - open set with $\alpha$-closed it can lead to set $\beta$ - open set. In [6] Ryszard Engelking introduced the function as concept to $\beta$ - continuous, $\mathrm{B}^{*} \mathrm{c}-$ continuous, $\beta$ - open function, $\mathrm{B}^{*} \mathrm{c}-$ open function, $\beta$ - closed function, $\mathrm{B}^{*} \mathrm{c}-$ closed function and find the relation among them.

\section{On B* ${ }^{*}$ - open sets}

\section{Definition (2.1) [1]} called to be

Let $\mathrm{X}$ be a top. sp. Then a sub set A of $\mathrm{X}$ is

i) a $\beta$ - open set if $\mathrm{A} \subseteq \overline{\bar{A}}^{0}$.

ii) a $\beta$-closed set if $\mathrm{A} \supseteq{\overline{A^{\circ}}}^{\circ}$

The all $\beta$ - open (resp. $\beta$ - closed) set sub sets of a space $\mathrm{X}$ will be as always symbolizes that $\beta \mathrm{o}(\mathrm{x})$ (resp. $\beta c(x)$ ).

\section{Example (2.2):}

Let $X=\{a, b, c, d\}$ with topology

$\mathrm{t}=\{\varnothing, \mathrm{X},\{\mathrm{a}\},\{\mathrm{a}, \mathrm{b}\},\{\mathrm{a}, \mathrm{c}, \mathrm{d}\}$. Then the clases of $\beta$ - open set and $\beta$ closed set are:

$\beta o(X)=\{\varnothing, X,\{a\},\{a, b\},\{a, c\},\{a, d\},\{a, b, c\},\{a$, $\mathrm{b}, \mathrm{d}\},\{\mathrm{a}, \mathrm{c}, \mathrm{d}\}$.

$\beta c(X)=\{\varnothing, X,\{b\},\{c\},\{d\},\{b, c\},\{b, d\},\{c, d\},\{b$, c, d\}.

\section{Remark (2.3):} open set.

Let $\mathrm{X}$ be a top. Sp. If $\overline{\mathrm{A}}=\mathrm{X}$, then $\mathrm{A}$ is $\beta$ -

\section{Remark (2.4):} set in X.

If $A \beta$ - open set in $X$, then $A^{C}$ is $\beta$ - closed

\section{Proposition (2.5):}

\section{Let $\mathrm{X}$ be a top. Sp. Then:}

i) Every open set is $\beta$ - open set in $X$.

ii) Every closed set is $\beta$ - closed set in $X$.

\section{Proof :}

i) Let $A$ be open set, then $A=A^{\circ}$. Since $A \subseteq \bar{A}$, then $\mathrm{A}=\mathrm{A}^{\circ} \subseteq \bar{A}^{o}$, there for $\mathrm{A} \subseteq \overline{\bar{A}}^{o}$, hence $\mathrm{A}$ is $\beta$ - open set inX. ii) Let $A$ be closed set, then $A^{C}$ open set, then $A^{C} \beta$ open set in $\mathrm{X}$ by (i), then $\mathrm{A} \beta$ - closed set in $\mathrm{X}$.

The converse of above proposition is not true in general.

\section{Example (2.6):}

Let $X=\{1,2,3\}, t=\{\varnothing, X,\{1\},\{2,3\}\}$. $\beta o(X)=\{\varnothing, X,\{1\},\{2\},\{3\},\{1,2\},\{1,3\},\{2,3\}\}$. $\beta C(X)=\beta o(X)$.

Note that $A=\{3\}$ is $\beta$ - open (resp. $\beta$ closed) set, but not open (resp. closed) set.

\section{Theorem (2.7):}

Let $\mathrm{X}$ be atop. Sp. Then the following statement are holds:

i) The union family of $\beta$ - open sets is $\beta$ - open set.

ii) The intersection family of $\beta$ - closed sets is $\beta$ closed set.

Proof:

i) Let $\left\{A_{\alpha}: \alpha \in \Lambda\right\}$ be a family of $\beta$-open set in $\mathrm{X}$, then $A_{\alpha} \subseteq \overline{\overline{A_{\alpha}}}$, then

$\bigcup_{\alpha \in \Lambda} A_{\alpha} \subseteq \bigcup_{\alpha \in \Lambda} \overline{\overline{A_{\alpha}}}=\overline{\bigcup_{\alpha \in \Lambda} \overline{A_{\alpha}} \subseteq \overline{\left[\bigcup_{\alpha \in \Lambda} \overline{A_{\alpha}}\right]^{o}}}=\overline{\bigcup_{\alpha \in \Lambda}^{o} A_{\alpha}}$ , hence $\bigcup_{\alpha \in \Lambda} A_{\alpha}$ is $\beta$-open set .

ii ) Let $\left\{A_{\alpha}: \alpha \in \Lambda\right\}$ be a family of $\beta$-closed set in $\mathrm{X}$, then $\left\{A_{\alpha}^{c}: \alpha \in \Lambda\right\}$ be $\beta$-open set in $\mathrm{X}$, then $\left\{\bigcup_{\alpha \in \Lambda} A_{\alpha}^{c}: \alpha \in \Lambda\right\} \beta$ - open sets .But $\left[\bigcap_{\alpha \in \Lambda} A_{\alpha}\right]^{c}=\bigcup_{\alpha \in \Lambda} A_{\alpha}^{c}$, then $\left[\bigcap_{\alpha \in \Lambda} A_{\alpha}\right]^{c} \beta-$ open sets in $\mathrm{X}$. There for $\bigcap_{\alpha \in \Lambda} A_{\alpha} \beta$-closed set in X.

\section{Remark (2.8):}

i) [1] the intersection of any two $\beta$ - open sets is not $\beta$ - open set in general.

ii) The union of any two $\beta$ - closed sets is not $\beta$ closed set in general.

\section{Example (2.9):}

$\{1,2\}\}$.

$$
\text { Let } X=\{1,2,3\}, t=\{\varnothing, X,\{1\},\{2\},
$$

$\beta o(X)=\{\varnothing, X,\{1\},\{2\},\{1,2\},\{1,3\},\{2,3\}\}$.

$\beta c(X)=\{\varnothing, X,\{1\},\{2\},\{3\},\{1,3\},\{2,3\}\}$.

i) Let $A=\{1,3\}, B=\{2,3\}$ are $\beta$ - open sets, but $A \cap$ $B=\{3\}$ not $\beta$ - open in $X$.

ii) Let $A=\{1\}, B=\{2\}$ are $\beta$ - closed sets, but $A \cup B$ $=\{1,2\}$ not $\beta$ - closed in $X$. 


\section{Proposition (2.10)}

Let $X$ be atop. Sp. Then:

i) $G$ is an open set in $X$ iff $\overline{G \cap \bar{A}}=\overline{G \cap A}$ for each $\mathrm{A} \subseteq \mathrm{X}$. [2]

\section{Proposition (2.11)}

\section{Let $\mathrm{X}$ be atop. Sp. Then:}

i) The intersection a $\beta$ - open set and open set in $X$ is $\beta$ - open set.

ii) The union a $\beta$ - closed set and closed set in $X$ is $\beta$ - closed set.

Proof:

i) Let $\mathrm{A}$ be a $\beta$ - open set, then $\mathrm{A} \subseteq \overline{\bar{A}}^{\mathrm{O}}$

Let $\mathrm{B}$ open set. Then

$$
\begin{aligned}
& \mathrm{A} \cap \mathrm{B} \subseteq\left(\overline{\bar{A}}^{\circ} \cap \mathrm{B}\right) \text {. }
\end{aligned}
$$

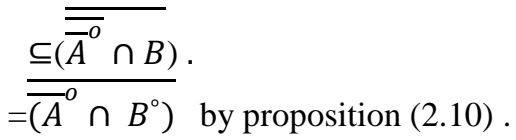

$$
\begin{aligned}
& =\overline{(\bar{A} \cap B)^{o}} \text {. } \\
& \subseteq \overline{(\bar{A} \cap B)}^{\circ} \text { by proposition (2.10) } \\
& =\overline{\overline{A \cap B}}^{\circ} \text { by proposition (2.10) }
\end{aligned}
$$

ii) Let $A$ be a $\beta$ - closed set in $X$, then $A^{C} \beta$ - open set in $\mathrm{X}$.

Let $\mathrm{B}$ be closed set in $\mathrm{X}$, then $\mathrm{B}^{\mathrm{C}}$ open set in $X$, then by (i) we get $A^{C} \cap B^{C} \beta$ - open set in $X$, but $(A \cup B)^{C}=\left(A^{C} \cap B^{C}\right)$, then $(A \cup B)^{C} \beta$ - open set in $X$, then $A \cup B \beta$ - closed set in $X$.

\section{Definition (2.12):}

Let $\mathrm{X}$ be atop. $\mathrm{Sp}$. and $\mathrm{A} \subseteq \mathrm{X}$. Then:

i) $\mathrm{A}$ is $\alpha$-open if $\mathrm{A} \subseteq{\overline{A^{O}}}^{O}$ [4].

ii) $\mathrm{A}$ is $\alpha$-closed if ${\overline{A^{O}}}^{O} \subseteq \mathrm{A}$ [4].

\section{Definition (2.13):}

Let $X$ be atop. Sp. $X$ and $A \subseteq X$. Then a $\beta$ open set $A$ is said a $B^{*} c$. open set if $\forall x \in A \exists F_{x}$ closed set $\ni \mathrm{x} \in \mathrm{F}_{\mathrm{x}} \subseteq \mathrm{A}$. $\mathrm{A}$ is a $\mathrm{B}^{*} \mathrm{c}$ - closed set if $\mathrm{A}^{\mathrm{c}}$ is a $B^{*} c-$ open set $X$.

The all $\mathrm{B}^{*} \mathrm{c}-$ open (resp. $\mathrm{B}^{*} \mathrm{c}-$ closed) set sub set of a space $\mathrm{X}$ will be as always symbolize $\mathrm{B}^{*} \mathrm{c}$ $\mathrm{O}(\mathrm{X})\left(\right.$ resp. $\left.{ }^{*} \operatorname{cc}(\mathrm{X})\right)$.

\section{Example (2.14):}

In example (2.9). Note that closed set in X are:

$\emptyset, X,\{2,3\},\{1,3\},\{3\}$. Then

$\mathrm{B}^{*} \mathrm{c} \mathrm{O}(\mathrm{X})=\{\varnothing, \mathrm{X},\{2,3\},\{1,3\}\}$

\section{Remark (2.15):} closed set in $\mathrm{X}$.

If $\mathrm{A} \mathrm{B}^{*} \mathrm{c}-$ open set in $\mathrm{X}$, then $\mathrm{A}^{\mathrm{C}}$ is $\mathrm{B}^{*} \mathrm{c}-$

\section{Remark (2.16):}

From definition (2.13). Note that:

i) Every $B^{*} c-$ open set is $\beta$ - open set.

ii) Every $B^{*} c-$ closed set is $\beta$ - closed set.
The converse of above Remark is not true in general.

\section{Example (2.17):}

Let $X=\{a, b, c\}, t=\{\varnothing, X,\{a\},\{b, c\}\}$. $\beta o(X)=\{\varnothing, X,\{a\},\{b\},\{c\},\{a, b\},\{a, c\},\{b, c\}\}$. $\beta c(X)=\beta o(X)$

$\mathrm{B}^{*} \mathrm{c} O(X)=\{\emptyset, X,\{a\},\{b, c\}\}$.

$\mathrm{B}^{*} \mathrm{c} C(\mathrm{X})=\mathrm{B}^{*} \mathrm{c} \mathrm{O}(\mathrm{X})$. Not that $\mathrm{A}=\{\mathrm{c}\}$ is $\beta$ - open (resp. $\beta$ - closed) ser. but not $\mathrm{B}^{*} \mathrm{c}-$ open (resp. $\mathrm{B}^{*} \mathrm{c}-$ closed) set.

\section{Remark (2.18):}

i) The $\mathrm{B}^{*} \mathrm{c}-$ open set and open set are in-dependent. ii) The $\mathrm{B}^{*} \mathrm{c}$ - closed set and closed set are independent.

\section{Example (2.19):}

In example (2.9) not that $\mathrm{B}^{*} \operatorname{co}(\mathrm{x})=\{\varnothing, \mathrm{X}$, $\{1,3\},\{2,3\}, B^{*} \operatorname{cc}(x)=\{\varnothing, X,\{1\},\{2\}\}$. Note that i) $\mathrm{A}=\{2,3\} \mathrm{B}^{*} \mathrm{c}-$ open set, but not open and $\mathrm{B}=$ $\{1\}$ is open, but not $\mathrm{B}^{*} \mathrm{c}-$ open.

ii) $\mathrm{A}=\{2\} \mathrm{B}^{*} \mathrm{c}-$ closed set, but not closed and $\mathrm{B}=$ $\{3\}$ is closed set, but not $B^{*} c-$ closed.

\section{Proposition (2.20):}

Let $\mathrm{X}$ be atop. Sp. and $\mathrm{A} \subseteq \mathrm{X}$. If $\mathrm{A} \alpha-$ closed. Then A $\beta$ - open in X iff $\mathrm{A} \mathrm{B}^{*} \mathrm{c}-$ open.

Proof:

Suppose that $\mathrm{A}$ a $\beta$-open set in $\mathrm{X}$, then $\mathrm{A} \subseteq$ $\overline{\bar{A}}^{\circ}$. Let $\mathrm{x} \in \mathrm{A} \subseteq \overline{\bar{A}}^{\circ}$. Since $\mathrm{x} \in \overline{\bar{A}^{o}}$ and $\mathrm{A} \alpha-$ closed set, then $\overline{\bar{A}^{o}} \subseteq \mathrm{A}$. Thus $\mathrm{x} \in \overline{\bar{A}}^{\circ} \subseteq \mathrm{A}, \exists \overline{\bar{A}}^{o}$ closed set $\ni \mathrm{x} \in \overline{\bar{A}}^{\circ} \subseteq \mathrm{A}$. Then $\mathrm{A} \mathrm{B}^{*} \mathrm{c}$ - open set. Conversely

Suppose that $\mathrm{A} \mathrm{B}^{*} \mathrm{c}$ - open set, then by definition (2.13), we get $A \beta$ - open.

\section{Corollary (2.21):}

If A open set and $\alpha-$ closed, then $\mathrm{A} \mathrm{B}^{*} \mathrm{c}-$ open.

Proof:

(2.20).
By proposition (2.5) (i) and proposition

\section{Proposition (2.22):}

Let $\mathrm{X}$ be atop. Sp. and $\mathrm{A} \subseteq \mathrm{X}$. If $\mathrm{A} \alpha-$ open. Then A $\beta$ - closed iff A B ${ }^{*} \mathrm{c}$ - closed.

\section{Proof:}

Let $A$ be $\beta$ - closed, then $A^{C} \beta$ - open. Since A $\alpha$-open, then $\mathrm{A}^{\mathrm{C}} \alpha$ - closed, then by proposition (2. 20), we get $A^{C} B^{*} c-$ open set. There fore $A \beta$ closed set.

\section{Corollary (2.23):} closed. If $\mathrm{A}$ closed set and $\alpha$-open, then $\mathrm{A} \mathrm{B}^{*} \mathrm{c}-$ Proof:

By proposition (2.5) (ii) and (2.22) 


\section{Proposition (2.24):}

\section{Let $X$ be atop. Sp. X. Then}

i) The union family of $\mathrm{B}^{*} \mathrm{c}-$ open set is $\mathrm{B}^{*} \mathrm{c}$ - open set.

ii) The intersection family $\mathrm{B}^{*} \mathrm{c}-$ closed set is $\mathrm{B}^{*} \mathrm{c}-$ closed set.

\section{Proof:}

i) Let $\left\{A_{\alpha}: \alpha \in \Lambda\right\}$ be a family of $B^{*} c-$ open sets, then $\left\{A_{\alpha}: \alpha \in \Lambda\right\}$ is $\beta$ - open sets, then $\bigcup_{\alpha \in \Lambda} A_{\alpha}$ is $\beta$ - open set by lemma (2.7) (i). Let $x \in$ $\bigcup_{\alpha \in \Lambda} A_{\alpha}$, then $x \in A_{\alpha}$ for some $\alpha \in \Lambda$. Since $A_{\alpha}$ $\mathrm{B}^{*} \mathrm{c}$ - open set $\forall \alpha \in \Lambda$, then $\exists \mathrm{F}$ closed set in $\mathrm{x} \exists \mathrm{x}$ $\in F \subseteq A_{\alpha} \subseteq U_{\alpha \in \Lambda}$ A. Then for $U_{\alpha \in \Lambda} A_{\alpha}$ is $B^{*} c$ open set.

ii) Let $\left\{\mathrm{A}_{\alpha}: \alpha \in \Lambda\right\}$ be a family of $\mathrm{B}^{*} \mathrm{c}-$ closed sets, then $\left\{A_{\alpha}^{\mathrm{c}}: \alpha \in \Lambda\right\}$ is a family of $\mathrm{B}^{*} \mathrm{c}$ - open sets, then $U_{\alpha \in \Lambda} A_{\alpha}^{c}$ is $B^{*} c$ - open sets by (i), them $\left[\bigcup_{\alpha \in \Lambda} A_{\alpha}^{c}\right] B^{*} c-$ closed. But $\bigcap_{\alpha \in \Lambda} A_{\alpha}=\left[U_{\alpha \in \Lambda} A_{\alpha}^{c}\right]^{c}$, then $\bigcap_{\alpha \in \Lambda} A_{\alpha}$ is $B^{*} c$ - closed in $X$.

\section{Remark (2.25):}

i) Not every intersection of two $\mathrm{B}^{*} \mathrm{c}-$ open set is $\mathrm{B}^{*} \mathrm{c}$ - open set.

ii) Not every union of two $\mathrm{B}^{*} \mathrm{c}-$ closed set is $\mathrm{B}^{*} \mathrm{c}-$ closed set.

\section{Example (2.26):}

In example (2.9)

$\mathrm{B}^{*} \mathrm{c} \mathrm{O}(\mathrm{X})=\{\varnothing, X,\{2,3\},\{1,3\}\}$.

$\mathrm{B}^{*} \mathrm{c} C \mathrm{C}(\mathrm{X})=\{\varnothing, \mathrm{X},\{1\},\{2\}\}$. Not that:

i) Let $A=\{1,3\}, B=\{2,3\}$ are $B^{*} c-$ open set, but $A$ $\cap B=\{3\}$ not $B^{*} c-$ open set in $X$.

ii) Let $A=\{1\}, B=\{2\}$ are $B^{*} c-$ closed set, but $A$ $\cup B=\{1,2\}$ not $B^{*} c-$ closed set in $X$.

\section{Definition (2.27):}

Let A subset of top. Sp. Then A is called:

i) Clopen set if A closed and open.[6]

ii) $\beta$ - Clopen set if $A \beta$ - closed and $\beta$ - open.

iii) $\mathrm{B}^{*} \mathrm{c}-$ Clopen set if $\mathrm{A} \mathrm{B}^{*} \mathrm{c}-$ closed and $\mathrm{B}^{*} \mathrm{c}-$ open.

\section{Proposition (2.28):[4]}

Let $\mathrm{X}$ be atop. $\mathrm{Sp}$. and $\mathrm{A} \subseteq \mathrm{X}$. Then

i) Every closed set is $\alpha$-closed set.

ii) Every open set is $\alpha$ - open set.

\section{Proposition (2.29):}

\section{Let $\mathrm{X}$ be atop. Sp. Then:}

i) The union $\mathrm{B}^{*} \mathrm{c}-$ open set and clopen set is $\mathrm{B}^{*} \mathrm{c}-$ open.

ii) The intersection $\mathrm{B}^{*} \mathrm{c}$ - closed set and clopen set is $\mathrm{B}^{*} \mathrm{c}-$ closed.

\section{Proof:}

i) Let $A B^{*} \mathrm{C}$ - open set, then $A^{C} B^{*} c$ - closed. Let B clopen, then $\mathrm{B}^{\mathrm{C}}$ clopen, then $\mathrm{B}^{\mathrm{C}}$ closed and open. Since $B^{C}$ closed, then $B^{C} \beta$ - closed. Since $B^{C}$ open, then $\mathrm{B}^{\mathrm{C}} \alpha$ - open by proposition (2.28) (ii), then $\mathrm{B}^{\mathrm{C}}$ $\mathrm{B}^{*} \mathrm{c}$ - closed, then $\mathrm{A}^{\mathrm{C}} \cap \mathrm{B}^{\mathrm{C}} \mathrm{B}^{*} \mathrm{c}$ - closed by proposition (2.22) (ii), then $\left(\mathrm{A}^{\mathrm{C}} \cap \mathrm{B}^{\mathrm{C}}\right)^{\mathrm{C}} \mathrm{B}^{*} \mathrm{c}$ - open.
But $A \cup B=\left(A^{C} \cap B^{C}\right)^{C}$, there for $A \cup B B^{*} \mathrm{c}-$ open set in $\mathrm{X}$.

ii) Let $\mathrm{A} \mathrm{B}^{*} \mathrm{c}-$ closed, then $\mathrm{A}^{\mathrm{C}} \mathrm{B}^{*} \mathrm{c}$ - open. Let $\mathrm{B}$ clopen, then $B^{C}$ clopen, then by (i), we get $A^{C} \cup B^{C}$ $\mathrm{B}^{*} \mathrm{c}$ - open, then $\left(\mathrm{A}^{\mathrm{C}} \cup \mathrm{B}^{\mathrm{C}}\right)^{\mathrm{C}} \mathrm{B}^{*} \mathrm{c}-$ closed. But $\mathrm{A} \cap$ $\mathrm{B}=\left(\mathrm{A}^{\mathrm{C}} \cup \mathrm{B}^{\mathrm{C}}\right)^{\mathrm{C}}$, then $\mathrm{A} \cap \mathrm{B} \mathrm{B}^{*} \mathrm{c}-$ closed.

\section{Proposition (2.30):}

Let $\mathrm{X}$ be atop. $\mathrm{Sp}$. Then:

i) The intersection $\mathrm{B}^{*} \mathrm{c}-$ open set and clopen is $\mathrm{B}^{*} \mathrm{c}$ - open set.

ii) The union $\mathrm{B}^{*} \mathrm{c}$ - closed set and clopen set is $\mathrm{B}^{*} \mathrm{c}$ closed.

\section{Proof:}

i) Let $\mathrm{A}$ be $\mathrm{B}^{*} \mathrm{c}$ - open set and $\mathrm{B}$ clopen, then $\mathrm{B}$ open and closed, then $A \beta$ - open set and $B$ open, then $A \cap B$ is $\beta$ - open set by (2.11)(i). Let $x \in A \cap$ $\mathrm{B}$, then $\mathrm{x} \in \mathrm{A}$ and $\mathrm{x} \in \mathrm{B}$, then $\exists \mathrm{F}$ closed set in $\mathrm{x} \ni \mathrm{x}$ $\in F \subseteq A$. Since $F \cap B$ is closed set in $x$, then $x \in F$ $\cap \mathrm{B} \subseteq \mathrm{A} \cap \mathrm{B}$, hence $\mathrm{A} \cap \mathrm{B} \mathrm{B}^{*} \mathrm{c}-$ open.

ii) Let $A B^{*} c$ - closed set, then $A^{C} B^{*} c$ - open. Let $B$ clopen in $X$, then $B^{C}$ clopen, then by (i) we get $A^{C} \cap$ $\mathrm{B}^{\mathrm{C}} \mathrm{B}^{*} \mathrm{c}$ - open in $\mathrm{X}$, then $\left(\mathrm{A}^{\mathrm{C}} \cup \mathrm{B}^{\mathrm{C}}\right)^{\mathrm{C}} \mathrm{B}^{*} \mathrm{c}-$ closed. But $A \cup B=\left(A^{C} \cap B^{C}\right)^{C}$, then $A \cup B B^{*} c-$ closed in $X$.

The following diagram shows the relation among types of open, closed sets.

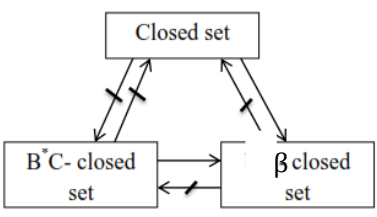

(a)

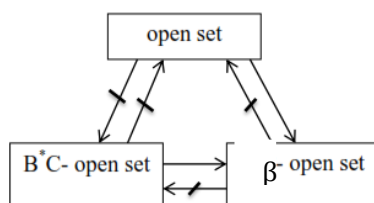

(b)
Definition (2.31): Then:

Let $\mathrm{F}: \mathrm{X} \rightarrow \mathrm{Y}$ be a function and $\mathrm{A} \subseteq \mathrm{X}$

i) $\mathrm{F}$ is called continuous function [6]. If $\forall \mathrm{A}$ open subset of $Y$, then $\mathrm{F}^{-1}(\mathrm{~A})$ is open subset of $\mathrm{X}$.

ii) $\mathrm{F}$ is called $\beta$ - continuous function. If $\forall A$ open subset of $Y$, then $F^{-1}(A)$ is $\beta$ - open subset of $X$.[1] iii) $\mathrm{F}$ is called $\mathrm{B}^{*} \mathrm{c}$-continuous function. If $\forall \mathrm{A}$ open subset of $\mathrm{Y}$, then $\mathrm{F}^{-1}(\mathrm{~A})$ is $\mathrm{B}^{*} \mathrm{c}$ - open subset of $\mathrm{X}$.

\section{Proposition (2.32):}

Let $\mathrm{F}: \mathrm{X} \rightarrow \mathrm{Y}$ be a function and $\mathrm{A} \subseteq \mathrm{X}$.

Then:

i) Every cont. function is a $\beta$ - cont.

ii) Every $\mathrm{B}^{*} \mathrm{c}$-cont. function is a $\beta$ - cont.

Proof:

Let $\mathrm{F}: \mathrm{X} \rightarrow \mathrm{Y}$ be a function

i) Let $\mathrm{F}$ cont. and Let $\mathrm{A}$ be open in $\mathrm{Y}$. Since $\mathrm{F}$ is cont. function, then $F^{-1}(A)$ is open in $X$, then $F^{-1}$ (A) is a $\beta$ - open in $X$. Hence $F$ is a $\beta$ - cont.

ii) Let $F B^{*} \mathrm{c}$-cont. and Let $\mathrm{A}$ be open in $\mathrm{Y}$. Since $\mathrm{F}$ $\mathrm{B}^{*} \mathrm{c}$-cont. function then $\mathrm{F}^{-1}$ (A) $\mathrm{B}^{*} \mathrm{c}$ - open in $\mathrm{X}$, then $F^{-1}$ (A) $\beta$ - open in $X$, hence $F$ is a $\beta$ - cont.

The converse of above proposition is not true in general. 


\section{Example (2.33)}

$2,3\}$

Let $\mathrm{F}: \mathrm{X} \rightarrow \mathrm{Y}$ be a function and let $\mathrm{X}=\{1$,

$\mathrm{t}=\{\varnothing, \mathrm{X},\{1\},\{2,3\}\}$.

$\beta o(X)=\{\varnothing, X,\{1\},\{2\},\{3\},\{1,2\},\{1,3\},\{2,3\}\}$.

$\mathrm{B}^{*} \mathrm{c}$ o $(\mathrm{X})=\{\varnothing, X,\{1\},\{2,3\}\}$.

$\mathrm{Y}=\{\mathrm{a}, \mathrm{b}, \mathrm{c}\}, \hat{\mathrm{t}}=\{\varnothing, \mathrm{Y},\{\mathrm{a}\},\{\mathrm{b}\},\{\mathrm{a}, \mathrm{b}\}\}$.

$\beta o(Y)=\{\varnothing, Y,\{a\},\{b\},\{a, b\},\{a, c\},\{b, c\}\}$.

$\mathrm{B}^{*} \mathrm{co}(\mathrm{Y})=\{\varnothing, \mathrm{Y},\{\mathrm{a}, \mathrm{c}\},\{\mathrm{b}, \mathrm{c}\}\}$.

Define $F(1)=a, F(2)=b, F(3)=C$.

Note that $\mathrm{F}$ is $\beta$ - cont. But

i) F not cont. Since $A=\{b\}$ open in $Y$, but $F^{-1}(A)$ not open in $\mathrm{X}$.

ii) $F$ not $B^{*} c$ - cont. Since $A=\{b\}$ open in $Y$, but $F^{-}$

${ }^{1}(\mathrm{~A})$ not $\mathrm{B}^{*} \mathrm{c}$ - open in $\mathrm{X}$.

Remark (2.34):

The continuous function and $\mathrm{B}^{*} \mathrm{c}$ -

continuous are independent in general.

\section{Example (2.35):}

Let $\mathrm{F}: \mathrm{X} \rightarrow \mathrm{Y}$ be a function

Let $X=\{1,2,3\}, t=\{\varnothing, X,\{1\},\{2\},\{1,2\},\{1,3\}\}$,

$\beta \mathrm{o}(\mathrm{x})=\mathrm{t}$.

$\mathrm{B}^{*} \operatorname{co}(\mathrm{x})=\{\varnothing, X,\{2\},\{1,3\}\}$.

$\mathrm{Y}=\{\mathrm{a}, \mathrm{b}, \mathrm{c}\}, \hat{\mathrm{t}}=\{\varnothing, \mathrm{Y},\{\mathrm{a}\},\{\mathrm{b}\},\{\mathrm{a}, \mathrm{b}\}\}$.

$\beta o(Y)=\{\varnothing, Y,\{a\},\{b\},\{a, b\},\{a, c\},\{b, c\}\}$.

$\mathrm{B}^{*} \operatorname{co}(\mathrm{Y})=\{\varnothing, \mathrm{Y},\{\mathrm{a}, \mathrm{c}\},\{\mathrm{b}, \mathrm{c}\}\}$.

Define $F(1)=a, F(2)=b, F(3)=C$.

Note that $\mathrm{F}$ is cont. function, but not $\mathrm{B}^{*} \mathrm{c}$ - cont. function. Since $A=\{a\}$ open in $Y$, but $F^{-1}(A)$ not $\mathrm{B}^{*} \mathrm{c}$ - open in $\mathrm{X}$.

\section{Example (2.36)}

$2,3\}$.

Let $F: X \rightarrow Y$ be a function and Let $X=\{1$,

$\mathrm{t}=\{\varnothing, \mathrm{X},\{1\},\{3\},\{1,3\}\}, \beta \mathrm{o}(\mathrm{X})=\{\varnothing, \mathrm{X},\{1\},\{3\}$,

$\{1,2\},\{1,3\},\{2,3\}\}$.

$\mathrm{B}^{*} \mathrm{c}$ o $(\mathrm{X})=\{\varnothing, X,\{1,2\},\{2,3\}\}$.

$\mathrm{Y}=\{\mathrm{a}, \mathrm{b}, \mathrm{c}\}, \hat{\mathrm{t}}=\{\varnothing, \mathrm{Y},\{\mathrm{a}, \mathrm{b}\}\}$.

Define $F(1)=a, F(2)=b, F(3)=C$.

Note that $F$ is $B^{*} c$ - cont. Since $A=\{a, b\}$ is open in $\mathrm{Y}$, but $\mathrm{F}^{-1}(\mathrm{~A})$ not open in $\mathrm{X}$.

The following diagram shows the relation among type of the continuous function.

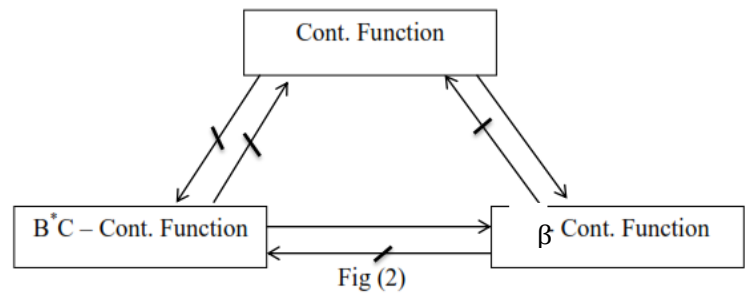

\section{3- The Closure:}

\section{Definition (3.1): [1]}

The intersection of all $\beta$ - closed set of atop. Sp. $X$ which is containing $A$ is called a $\beta$ - closure of A and denoted by $\overline{\mathrm{A}}^{\beta}$.

i. e $\bar{A}^{\beta}=\cap\{F: A \subseteq F, F$ is $\beta$ - closed in $X\}$.

\section{Definition (3.2):}

The intersection of all $\mathrm{B}^{*} \mathrm{c}$ - closed set of atop. Sp. $\mathrm{X}$ which is containing $\mathrm{A}$ is said a $\mathrm{B}^{*} \mathrm{c}$ closure of $A$ and denoted by $\overline{\mathrm{A}}^{\mathrm{B}^{*} \mathrm{C}}$.

i. $e \bar{A}^{B^{*} C}=\cap\left\{F: A \subseteq F, F\right.$ is $B^{*} c-$ closed in $\left.X\right\}$.

Lemma (3.3):

Let $X$ be atop. Sp. and $A \subseteq X$. Then

i) $X \in \bar{A}^{\beta}$ iff $\forall \beta$ - open set $G$ and $x \in G \ni G \cap A \neq$ $\emptyset[1]$.

ii) $\mathrm{X} \in \overline{\mathrm{A}}^{\mathrm{B}^{*} \mathrm{C}}$ iff $\forall \mathrm{B}^{*} \mathrm{c}$ - open set $\mathrm{G}$ and $\mathrm{x} \in \mathrm{G} \ni \mathrm{G} \cap$ $A \neq \varnothing$.

Proof:

ii) Let $x \notin \bar{A}^{B^{*} C}$, then $x \notin \cap F \ni F$ is $B^{*} c-$ closed set and $\mathrm{A} \subseteq \mathrm{F}$, then $\mathrm{x} \in[\cap \mathrm{F}]^{\mathrm{C}} \ni[\cap \mathrm{F}]^{\mathrm{C}}$ is $\mathrm{B}^{*} \mathrm{c}-$ open containing $\mathrm{X}$. Hence

$[\cap F]^{\mathrm{C}} \cap \mathrm{A} \subseteq[\cap \mathrm{F}]^{\mathrm{C}} \cap[\cap \mathrm{F}]=\emptyset$.

Conversely

Suppose that $\exists$ a $B^{*} c-$ open set $G \ni x \in G$ and $A \cap$ $\mathrm{G}=\varnothing$., then $\mathrm{A} \subseteq \mathrm{G}^{\mathrm{c}} \ni \mathrm{G}^{\mathrm{c}}$ is $\mathrm{B}^{*} \mathrm{c}$ - closed set, hence $\mathrm{x} \notin \overline{\mathrm{A}}^{\mathrm{B}^{*} \mathrm{C}}$

\section{Remark (3.4):}

Then

Let $\mathrm{X}$ be a topological space and $\mathrm{A} \subseteq \mathrm{X}$.

i) $\bar{A}^{\beta}$ is $\beta$ - closed set and $\bar{A}^{B^{*} C}$ is $B^{*} c$ - closed set.

ii) $\bar{A}^{\beta}$ (resp. $\bar{A}^{B^{*} C}$ ) is the smallest $\beta$ - closed (resp. $\mathrm{B}^{*} \mathrm{c}$ - closed) set containing $\mathrm{A}$.

iii) $\mathrm{A} \subseteq \overline{\mathrm{A}}^{\beta}$ also $\mathrm{A} \subseteq \overline{\mathrm{A}}^{\mathrm{B}^{*} \mathrm{C}} . \forall \mathrm{A} \subseteq \mathrm{X}$.

Proof:

Clear.

\section{Proposition (3.5):}

Let $\mathrm{X}$ be a top. Sp. $\mathrm{X}$ and $\mathrm{A} \subseteq \mathrm{X}$. Then:

i) $A \beta$ - closed set iff $A=\bar{A}^{\beta}[1]$.

ii) $A B^{*} c-$ closed set iff $A=\bar{A}^{B^{*} C}$.

Proof:

ii) Let $A$ be $B^{*} \mathrm{c}-$ closed set

Let $X \notin A$, then $X \in A^{C}$, then $\exists B^{*} c-$ open set $A^{\mathrm{C}} \ni \mathrm{A}^{\mathrm{C}} \cap \mathrm{A}=\emptyset$, then $\mathrm{X} \notin \overline{\mathrm{A}}^{\mathrm{B}^{*} \mathrm{C}}$, then $\overline{\mathrm{A}}^{\mathrm{B}^{*} \mathrm{C}} \subseteq$ A. Since $A \subseteq \bar{A}^{B^{*} C}$ by Remark (3.4) (iii). Hence $A=$ $\overline{\mathrm{A}}^{\mathrm{B}^{*} \mathrm{C}}$.

Conversely

Let $A=\bar{A}^{B^{*} C}$. Since $\bar{A}^{B^{*} C} B^{*} c-$ closed set in $\mathrm{X}$ and $\mathrm{A}=\overline{\mathrm{A}}^{\mathrm{B}^{*} \mathrm{C}}$, then $\mathrm{A} \mathrm{B}^{*} \mathrm{C}-$ closed set.

\section{Proposition (3.6):}

Let $\mathrm{X}$ be a top. Sp. $\mathrm{X}$ and $\mathrm{A} \subseteq \mathrm{X}$. Then:

i) $\overline{\overline{\mathrm{A}}}^{\beta}=\overline{\mathrm{A}}^{\beta} \quad[1]$.

ii) If $\mathrm{A} \subseteq \mathrm{B}$, then $\overline{\mathrm{A}}^{\beta} \subseteq \overline{\mathrm{B}}^{\beta}$.

\section{Proof:}

ii) Let $\mathrm{A} \subseteq \mathrm{B}$. Since $\mathrm{B} \subseteq \overline{\mathrm{B}}^{\beta}$ by Remark (3.4) (iii), then $\mathrm{A} \subseteq \overline{\mathrm{B}}^{\beta}$.

Since $\overline{\mathrm{B}}^{\beta}$ is $\beta$ - closed in $\mathrm{X}$ and $\overline{\mathrm{A}}^{\beta}$ is the smallest $\beta$ - closed set containing $A$. There for $\overline{\mathrm{A}}^{\beta} \subseteq \overline{\mathrm{B}}^{\beta}$. 


\section{Proposition (3.7):}

i) $\overline{\overline{\mathrm{A}}}^{\mathrm{B}^{*} \mathrm{~B}}{ }^{*} c=\overline{\mathrm{A}}^{\mathrm{B}^{*} \mathrm{C}}$

ii) If $\mathrm{A} \subseteq \mathrm{B}$, then $\overline{\mathrm{A}}^{\mathrm{B}^{*} \mathrm{C}} \subseteq \overline{\mathrm{B}}^{\mathrm{B}^{*} \mathrm{C}}$.

Proof:

i) Since $\bar{A}^{B^{*} C}$ is $B^{*} c$ - closed, then by proposition (3.5) (ii), we get the result.

ii) Let $\mathrm{A} \subseteq \mathrm{B}$. Since $\mathrm{B} \subseteq \overline{\mathrm{B}}^{\beta}$ by Remark (3.4) (iii), then $\mathrm{A} \subseteq \overline{\mathrm{B}}^{\mathrm{B}^{*} \mathrm{C}}$.

Since $\bar{B}^{B^{*} C}$ is $B^{*} c$ - closed and $\bar{A}^{B^{*} C}$ is the smallest $\mathrm{B}^{*} \mathrm{c}-$ closed containing $\mathrm{A}$. Then fore $\overline{\mathrm{A}}^{\mathrm{B}^{*} \mathrm{C}} \subseteq \overline{\mathrm{B}}^{\mathrm{B}^{*} \mathrm{C}}$.

\section{Proposition (3.8)}

Let $\mathrm{F}: \mathrm{X} \rightarrow \mathrm{Y}$ be function. Then the following statements are equivalent.

i) $\mathrm{F}$ is $\beta$ - continuous.

ii) $\mathrm{F}^{-1}$ (B) is $\beta$ - closed in $\mathrm{X} \forall \mathrm{B}$ is closed set in $\mathrm{Y}$.

iii) $\mathrm{F}\left(\overline{\mathrm{A}}^{\beta}\right) \subseteq \overline{\mathrm{F}(\mathrm{A})} \forall \mathrm{A} \subseteq \mathrm{X}$.

iv) ${\overline{\mathrm{F}^{-1}(\mathrm{~B})}}^{\beta} \subseteq \mathrm{F}^{-1}(\overline{\mathrm{B}}) \forall \mathrm{B} \subseteq \mathrm{Y}$.

\section{Proof:}

(i) (ii)

Let $\mathrm{B}$ be closed set in $\mathrm{Y}$, then $\mathrm{Y}-\mathrm{B}$ is open set in $\mathrm{Y}$, then $\mathrm{F}^{-1}(\mathrm{Y}-\mathrm{B})$ is a $\beta$ - open in $\mathrm{X}$ by (i), then $\mathrm{X}-\mathrm{F}^{-1}(\mathrm{~B})$ is a $\beta$ - open in $\mathrm{X}$.

Then $F^{-1}(B)$ is a $\beta$ - closed in $X$.

(ii) (iii)

Let $\mathrm{A} \subseteq \mathrm{X}$, then $\mathrm{F}(\mathrm{A}) \subseteq \mathrm{Y}$, then $\overline{\mathrm{F}(\mathrm{A})}$ is closed set in $Y$, then $F^{-1}(\overline{F(A)})$ is a $\beta$ - closed set in $X$ by (ii). Since $F(A) \subseteq \overline{F(A)}$, Then $A \subseteq F^{-1}(\overline{F(A)})$, then $\bar{A}^{\beta} \subseteq \mathrm{F}^{-1}(\overline{\mathrm{F}(\mathrm{A})})$, there fore $\mathrm{F}\left(\overline{\mathrm{A}}^{\beta}\right) \subseteq \overline{\mathrm{F}(\mathrm{A})}$.

(iii) $\longrightarrow$ (iv)

Let $\mathrm{B} \subseteq \mathrm{Y}$, then $\mathrm{F}^{-1}(\mathrm{~B}) \subseteq \mathrm{X}$, then $\mathrm{F}\left[{\overline{\left.\mathrm{F}^{-1}(\mathrm{~B})\right]}}^{\beta} \subseteq \mathrm{F}\left[\overline{\mathrm{F}^{-1}(\mathrm{~B})}\right]\right.$ by (iii), then $\mathrm{F}$

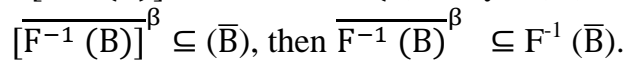

(iv) (i)

Let $\mathrm{B}$ be open set in $\mathrm{Y}$, then $\mathrm{Y}-\mathrm{B}$ is closed set in Y. Then

${\overline{F^{-1}}(\mathrm{Y}-\mathrm{B})}^{\beta} \subseteq \mathrm{F}^{-1}(\overline{\mathrm{Y}-\mathrm{B}})=\mathrm{F}^{-1}(\mathrm{Y}-\mathrm{B})$. Since $\mathrm{F}^{-1}$ $(\mathrm{Y}-\mathrm{B})=\mathrm{X}-\mathrm{F}^{-1}(\mathrm{~B})$ is a $\beta$ - closed set in $\mathrm{X}$, then $\mathrm{F}^{-1}$ (B) is a $\beta$ - open set in $X$.

There fore $F$ is a $\beta$ - continuous.

\section{Proposition (3.9)}

Let $\mathrm{F}: \mathrm{X} \rightarrow \mathrm{Y}$ be a function. Then the following statements are equivalent.

i) $\mathrm{F}$ is $\mathrm{BC}$ - continuous.

ii) $\mathrm{F}^{-1}(\mathrm{~B})$ is $\mathrm{B}^{*} \mathrm{c}$ - closed in $\mathrm{X} \forall \mathrm{B}$ is closed set in $\mathrm{Y}$.

iii) $\mathrm{F}\left(\overline{\mathrm{A}}^{\mathrm{B}^{*} \mathrm{C}}\right) \subseteq \overline{\mathrm{F}(\mathrm{A})} \forall \mathrm{A} \subseteq \mathrm{X}$.

iv) ${\overline{\mathrm{F}^{-1}(\mathrm{~B})}}^{\mathrm{B}^{*} \mathrm{c}} \subseteq \mathrm{F}^{-1}(\overline{\mathrm{B}}) \forall \mathrm{B} \subseteq \mathrm{Y}$.

Proof:

(i) (ii)

Let $\mathrm{B}$ be closed set in $\mathrm{Y}$, then $\mathrm{Y}-\mathrm{B}$ is open set in $Y$, then $F^{-1}(Y-B)$ is a $B^{*} c-$ open in $X$ by (i), then $\mathrm{X}-\mathrm{F}^{-1}(\mathrm{~B})$ is a $\mathrm{B}^{*} \mathrm{c}$ - open in $\mathrm{X}$.
Hence $\mathrm{F}^{-1}(\mathrm{~B})$ is a $\mathrm{B}^{*} \mathrm{c}$ - closed in $\mathrm{X}$.

(ii) - (iii)

Let $\mathrm{A} \subseteq \mathrm{X}$, then $\mathrm{F}(\mathrm{A}) \subseteq \mathrm{Y}$, then $\overline{\mathrm{F}(\mathrm{A})}$ is closed set in $\mathrm{Y}$, then $\mathrm{F}^{-1}(\overline{\mathrm{F}(\mathrm{A})})$ is a $\mathrm{BC}$ - closed set in $X$ by (ii). Since $F(A) \subseteq \overline{F(A)}$, Then $A \subseteq F^{-1}(\overline{F(A)})$, then $\overline{\mathrm{A}}^{\mathrm{B}^{*} \mathrm{C}} \subseteq \mathrm{F}^{-1}(\overline{\mathrm{F}(\mathrm{A})})$, hence $\mathrm{F}\left(\overline{\mathrm{A}}^{\mathrm{B}^{*} \mathrm{C}}\right) \subseteq \overline{\mathrm{F}(\mathrm{A})}$.

(iii) $($ iv)

Let $\mathrm{B} \subseteq \mathrm{Y}, \quad$ then $\mathrm{F}^{-1}(\mathrm{Y}) \subseteq \mathrm{X}, \quad$ then ${\overline{\mathrm{F}\left[\mathrm{F}^{-1}(\mathrm{~B})\right]}}^{\mathrm{B}^{*} \mathrm{c}} \subseteq \mathrm{F}\left[\overline{\mathrm{F}^{-1}(\mathrm{~B})}\right]$, then ${\overline{\mathrm{F}\left[\mathrm{F}^{-1}(\mathrm{~B})\right]}}^{\mathrm{B}^{*} \mathrm{c}} \subseteq$ $\overline{\mathrm{B}}$, then ${\overline{\mathrm{F}^{-1}(\mathrm{~B})}}^{\mathrm{B}^{*} \mathrm{c}} \subseteq \mathrm{F}^{-1}(\overline{\mathrm{B}})$.

(iv) (i)

Let $\mathrm{B}$ be open set in $\mathrm{Y}$, then $\mathrm{Y}-\mathrm{B}$ is closed set in Y. Then

$\overline{\mathrm{F}}-1(\mathrm{Y}-\mathrm{B})^{\mathrm{B}^{*} c} \subseteq \mathrm{F}^{-1}(\overline{\mathrm{Y}-\mathrm{B}})=\mathrm{F}^{-1}(\mathrm{Y}-\mathrm{B})$, then $\mathrm{F}^{-1}$ $(\mathrm{Y}-\mathrm{B})=\mathrm{X}-\mathrm{F}^{-1}(\mathrm{~B})$ is a $\mathrm{BC}$ - closed set in $\mathrm{X} . \mathrm{F}^{-1}$ (B) is a BC-open set in $\mathrm{X}$.

There fore $\mathrm{F}$ is a $\mathrm{B}^{*} \mathrm{c}$ - continuous.

\section{Definition (3.10):}

Then:

Let $\mathrm{F}: \mathrm{X} \rightarrow \mathrm{Y}$ be function and $\mathrm{A} \subseteq \mathrm{X}$.

i) $\mathrm{F}$ is called open (resp. closed) [6] . If $\forall \mathrm{A}$ open (resp. closed), subset of $\mathrm{X}$, then $\mathrm{F}(\mathrm{A})$ is open (resp. closed) subset of $\mathrm{Y}$

ii) $\mathrm{F}$ is called $\beta$ - open (resp. $\beta$ - closed). If $\forall \mathrm{A}$ open (resp. closed), subset of $X$, then $F(A)$ is $\beta$ - open (resp. $\beta$ - closed) subset of Y.

iii) $\mathrm{F}$ is called $\mathrm{B}^{*} \mathrm{c}$ - open (resp. $\mathrm{B}^{*} \mathrm{c}$ - closed). If $\forall \mathrm{A}$ open (resp. closed), subset of $\mathrm{X}$, then $\mathrm{F}(\mathrm{A})$ is $\mathrm{B}^{*} \mathrm{c}$ open (resp. B ${ }^{*} \mathrm{c}$ - closed) subset of $\mathrm{Y}$.

\section{Proposition (3.11):}

Let $\mathrm{F}: \mathrm{X} \rightarrow \mathrm{Y}$ be a function and $\mathrm{A} \subseteq \mathrm{X}$

Then:

i) Every open function is $\beta$ - open.

ii) Every closed function is $\beta$ - closed.

iii) Every $B^{*} c-$ open function is $\beta$ - open.

iv) Every $B^{*} \mathrm{c}-$ closed function is $\beta$ - closed.

Proof:

i) Let $\mathrm{F}: \mathrm{X} \rightarrow \mathrm{Y}$ be a function.

Suppose that $\mathrm{F}$ open function and let $\mathrm{A}$ open in $\mathrm{X}$. Since $F$ open, then $F(A)$ open in $Y$, then $F(A) \beta$ open in $\mathrm{Y}$. Thus $\mathrm{F}$ is $\beta$ - open.

ii) Similarly part (i).

iii) Suppose $F$ is $B^{*} c$ - open function and let $A$ open in $X$. Since $F B^{*} c$ - open, then $F(A) B^{*} c$ - open in $Y$, then $F(A) \beta$ - open in $Y$. Thus $F$ is $\beta$ - open.

iv) Similarly part (iii).

The Converse above proposition is not true in general.

\section{Example (3.12):}

In example $(2.34)$

Closed set in $X$ are: $\emptyset, X,\{2,3\},\{1\}$.

Closed set in Y are: $\emptyset, Y: \emptyset, X,\{b, c\},\{a, c\},\{c\}$.

$\beta c(Y)=\{\varnothing, Y,\{b, c\},\{a, c\},\{c\},\{b\},\{a\}\}$.

$\mathrm{B}^{*} \mathrm{c}(\mathrm{Y})=\{\varnothing, \mathrm{Y},\{\mathrm{b}\},\{\mathrm{a}\}\}$. 
Raad .A/Karim .F

Not that:

i) $F \beta$ - open, but not open since $A=\{2,3\}$ open in $\mathrm{X}$, but $\mathrm{F}(\mathrm{A})$ not open in $\mathrm{Y}$.

ii) $F \beta$ - closed, but not closed. Since $A=\{1\}$ closed set in $\mathrm{X}$, but $\mathrm{F}(\mathrm{A})$ not closed set in $\mathrm{Y}$.

iii) $F \quad \beta$ - open, but not $B^{*} c-$ open. Since $A=\{1\}$ open in $\mathrm{X}$, but $\mathrm{F}(\mathrm{A})$ not $\mathrm{B}^{*} \mathrm{c}$ - open set in $\mathrm{Y}$.

iv) $F \quad \beta$ - closed, but not $B^{*} c-$ closed. Since $A=\{2$, $3\}$ is closed in $\mathrm{X}$, but $\mathrm{F}(\mathrm{A})$ not $\mathrm{B}^{*} \mathrm{c}-$ closed in $\mathrm{Y}$.

\section{Remark (3.13):}

i) The open function and $\mathrm{B}^{*} \mathrm{c}-$ open function are independent.

ii) The closed function and $\mathrm{B}^{*} \mathrm{c}-$ open function are independent. We can showing that with two the following examples.

\section{Example (3.14):}

i) Let $F: X \rightarrow Y$ be function and let $X=\{a, b, c\}$

$\mathrm{t}=\{\varnothing, \mathrm{X},\{\mathrm{b}\},\{\mathrm{b}, \mathrm{c}\}\}, \beta \mathrm{o}(\mathrm{x})=\{\varnothing, \mathrm{X},\{\mathrm{b}\},\{\mathrm{a}, \mathrm{b}\}$, $\{b, c\}\}$.

$\mathrm{B}^{*} \operatorname{co}(\mathrm{X})=\{\varnothing, \mathrm{X}\}$.

$\mathrm{Y}=\{1,2,3\}, \hat{\mathrm{t}}=\{\varnothing, \mathrm{Y},\{2\},\{3\},\{2,3\},\{1,2\}\}$.

$\beta \mathrm{o}(\mathrm{Y})=\{\varnothing, \mathrm{Y},\{2\},\{3\},\{1,2\},\{2,3\}\}$.

$\mathrm{B}^{*} \operatorname{co}(\mathrm{Y})=\{\varnothing, \mathrm{Y},\{3\},\{1,2\}\}$.

Define $\mathrm{F}(\mathrm{a})=1, \mathrm{~F}(\mathrm{~b})=2, \mathrm{~F}(\mathrm{c})=3$.

ii) Let $F: X \rightarrow Y$ be a function and let $X=\{a, b, c\}$ $\mathrm{t}=\{\varnothing, \mathrm{X},\{\mathrm{b}, \mathrm{c}\}\}, \quad \beta \mathrm{o}(\mathrm{x})=\{\varnothing, \mathrm{X},\{\mathrm{b}\},\{\mathrm{c}\},\{\mathrm{a}, \mathrm{b}\}$, $\{a, c\},\{b, c\}\}$.

$\mathrm{B}^{*} \operatorname{co}(\mathrm{X})=\{\varnothing, \mathrm{X}\}$.

$\mathrm{Y}=\{1,2,3\}, \mathfrak{t}=\{\varnothing, \mathrm{Y},\{1\},\{3\},\{1,3\}\}$.

$\beta \mathrm{o}(\mathrm{Y})=\{\varnothing, \mathrm{Y},\{1\},\{3\},\{1,3\},\{2,3\}\}, \mathrm{B}^{*} \operatorname{co}(\mathrm{Y})$ $=\{\varnothing, \mathrm{Y},\{2,3\}\}$.

Define $F(a)=1, F(b)=2, F(c)=3$.

In example (i). Note that:

1) $F$ - open, but not $B^{*} c-$ open. Since $A=\{b\}$ open in $\mathrm{X}$, but $\mathrm{F}(\mathrm{A})$ not $\mathrm{B}^{*} \mathrm{c}$ - open set in $\mathrm{Y}$.

2) $\mathrm{F} \mathrm{b}^{*}$-closed, but not $B^{*} \mathrm{c}$-closed. Since $A=\{a\}$ closed set in $\mathrm{X}$, but $\mathrm{F}(\mathrm{A})$ not $\mathrm{B}^{*} \mathrm{c}-$-closed in $\mathrm{Y}$.

In example (ii). Note that:

1) $F B^{*} c-$ open, but not open. Since $A=\{b, c\}$ open in $\mathrm{X}$, but $\mathrm{F}(\mathrm{A})$ not open set in $\mathrm{Y}$.

2) $F B^{*} c$ - closed, but not closed. Since $A=\{a\}$ closed in $\mathrm{X}$, but $\mathrm{F}(\mathrm{A})$ not closed in $\mathrm{Y}$.

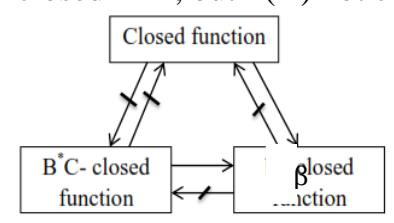

Fig (5)
Fig (4)

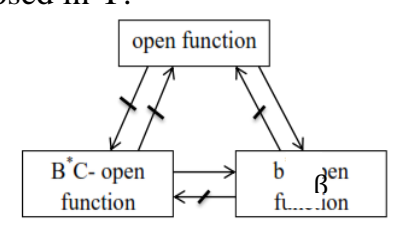

\section{4- The interior:}

\section{Definition (4.1):[1]}

The union of all $\beta$ - open set of atop. Sp. X contained in $\mathrm{A}$ is called $\beta$ - interior of $\mathrm{A}$ and denoted $\mathrm{A}^{\mathrm{o} \beta}$.

i.e

$\mathrm{A}^{\mathrm{o} \beta}=\mathrm{U}\{\mathrm{U}: \mathrm{U} \subseteq \mathrm{A}$ and $\mathrm{U} \beta$ - open set in $\mathrm{X}\}$.

\section{Definition (4.2):}

The union of all $\mathrm{B}^{*} \mathrm{c}$ - open set of atop. Sp. $\mathrm{X}$ contained in $\mathrm{A}$ is called $\mathrm{B}^{*} \mathrm{c}$ - interior of $\mathrm{A}$ and denoted $\mathrm{A}^{\mathrm{oB} \mathrm{B}^{*} \mathrm{C}}$.

i.e

$\mathrm{A}^{\mathrm{oB}{ }^{*} c}=U\{\mathrm{U}: \mathrm{U} \subseteq \mathrm{A}$ and $\mathrm{U} \mathrm{BC}$ - open set in $\mathrm{X}\}$.

\section{Proposition (4.3):}

Let $X$ be atop. Sp. and $A \subseteq X$. Then:

i) $X \in A^{o \beta}$ iff $\exists G \beta$ - open in $X \ni x \in G \subseteq A$. [1]

ii) $X \in A^{o B^{*} C}$ iff $\exists G B^{*} c$-open in $X \ni x \in G \subseteq A$.

Proof:

ii) Let $X \in A^{o B^{*} C}$

Since $A^{o B^{*} C}=U\left\{G: G \subseteq A, G\right.$ is $B^{*} c$ - open set in $\mathrm{X}\}$.

Then $\mathrm{z} \in U\left\{\mathrm{G}: \mathrm{G} \subseteq \mathrm{A}, \mathrm{G}\right.$ is $\mathrm{B}^{*} \mathrm{c}$ - open set in $\left.\mathrm{X}\right\}$.

Then $\exists \mathrm{GB}^{*} \mathrm{c}-$ open in $\mathrm{X} \ni \mathrm{X} \in \mathrm{G} \subseteq \mathrm{A}$.

Conversely

\section{$\mathrm{G} \subseteq \mathrm{A}$. Then}

Let $\mathrm{X} \in \mathrm{G} \subseteq \mathrm{A}$ and $\mathrm{G}$ is $\mathrm{B}^{*} \mathrm{c}-$ open in $\mathrm{x} \in$

$\mathrm{X} \in \mathrm{U}\left\{\mathrm{G}: \mathrm{G} \subseteq \mathrm{A}, \mathrm{G}\right.$ is $\mathrm{B}^{*} \mathrm{c}$ - open set in $\left.\mathrm{X}\right\}$.

There fore $X \in A \mathrm{OB}^{*} \mathrm{C}$.

\section{Remark (4.4):}

Let $\mathrm{x}$ be atop. Sp. and $\mathrm{A} \subseteq \mathrm{X}$. Then:

i) $A^{o \beta}$ is $\beta$ - open set and $A^{o B^{*} C}$ is $B^{*} c$ - open set.

ii) $A^{o \beta}$ (resp. $A^{o B^{*} C}$ ) is the largest $\beta$ - open (resp. $B^{*} c$ - open) set contained $A$.

iii) $\mathrm{A}^{\mathrm{o} \beta} \subseteq \mathrm{A}$ also $\mathrm{A} \subseteq \mathrm{A}^{\mathrm{oB}} \mathrm{C}$.

\section{Proof:}

Clear.

\section{Lemma (4.5): [1]}

Let $\mathrm{X}$ be atop. Sp. and $\mathrm{A} \subseteq \mathrm{X}$. Then

i) $\left[\mathrm{A}^{\mathrm{o} \beta}\right]^{\mathrm{C}}={\overline{\mathrm{A}^{\mathrm{C}}}}^{\beta}$.

ii) $\left[\overline{\mathrm{A}}^{\beta}\right]^{\mathrm{C}}=\mathrm{A}^{\mathrm{C}^{o \beta}}$

\section{Remark (4.6):}

i) $\left[\mathrm{A}^{\mathrm{oB}{ }^{*} \mathrm{C}}\right]^{\mathrm{C}}={\overline{\mathrm{A}^{\mathrm{C}}}}^{\mathrm{B}^{*} \mathrm{C}}$

ii) $\left[\bar{A}^{B^{*} C}\right]^{C}=A^{C^{O B * C}}$

\section{Proposition (4.7):}

Let $X$ be atop. Sp. and $A \subseteq X$. Then:

i) $A \beta$ - open set iff $A=A^{o \beta}$.[1]

ii) i) $A B^{*} c$ - open set iff $A=A^{o B^{*} C}$. 
Raad .A/Karim .F

\section{Proof:}

ii) Let $\mathrm{A} \mathrm{B}^{*} \mathrm{c}$ - open set, then $\mathrm{A}^{\mathrm{C}} \mathrm{B}^{*} \mathrm{c}$ - closed set, then by Remark (3.4) (iii), we have $\mathrm{A}^{\mathrm{C}}=\overline{\mathrm{A}^{\mathrm{C}}} \mathrm{B}^{*} \mathrm{C}$. Since $\overline{\mathrm{A}^{\mathrm{C}}} \mathrm{B}^{*} \mathrm{C}=\left[\mathrm{A}^{\mathrm{o} \mathrm{B}^{*} \mathrm{C}}\right]^{\mathrm{C}}$ by Remark (4.6) (ii), then $A^{C}=\left[A^{o B^{*} C}\right]^{C}$, hence $A=A^{o B^{*} C}$.

Conversely

Supposedly that $A=A^{o B^{*} C}$.

Since $A^{o B^{*} C}$ is $B^{*} c-$ open set and $A=A^{o B^{*} C}$, then $\mathrm{B}^{*} \mathrm{c}$ - open set.

\section{Proposition (4.8):}

Let $X$ be atop. Sp. and $A, B \subseteq X$. Then

i) $\left[\mathrm{A}^{\mathrm{o} \beta}\right]^{\mathrm{o} \beta}=\mathrm{A}^{\mathrm{o} \beta}[1]$.

ii) If $\mathrm{A} \subseteq \mathrm{B}$, then $\mathrm{A}^{\mathrm{o} \beta} \subseteq \mathrm{B}^{\mathrm{o} \beta}$.

Proof:

ii) Let $A \subseteq B$. Since $A^{o \beta} \subseteq A \subseteq B$, then $A^{o \beta} \subseteq B$. Since $B^{o \beta}$ is the largest $\beta$ - open set contained $B$, them $\mathrm{A}^{\mathrm{o} \beta} \subseteq \mathrm{B}^{\mathrm{o} \beta}$.

\section{Proposition (4.9):}

Let $X$ be atop. Sp. and $A, B \subseteq X$. Then

i) $\left[\mathrm{A}^{\mathrm{oB} \mathrm{B}^{*} \mathrm{C}}\right]^{\mathrm{oB} \mathrm{B} C}=\mathrm{A}^{\mathrm{oB} \mathrm{C}}$

ii) If $\mathrm{A} \subseteq \mathrm{B}$, then $\mathrm{A}^{\mathrm{oB} \mathrm{B}^{*} \mathrm{C}} \subseteq \mathrm{B}^{\mathrm{oB}} \mathrm{B}^{*} \mathrm{C}$.

Proof:

i) Since $A^{o B^{*} C}$ is $B C$ - open set, then $A^{o B^{*} C} \subseteq B$. Since $B^{o B^{*} C}$ is the largest $B^{*} c$ - open set contained $\mathrm{B}$, then $\mathrm{A}^{\mathrm{OB}{ }^{*} \mathrm{C}} \subseteq \mathrm{B}^{\mathrm{oB}{ }^{*} \mathrm{C}}$.

\section{Proposition (4.10):}

Let $\mathrm{F}: \mathrm{X} \rightarrow \mathrm{Y}$ be function. Then the following statement are equivalent.

i) $\mathrm{F} \beta$ - open function.

ii) $\mathrm{F}\left(\mathrm{A}^{\circ}\right) \subseteq[\mathrm{F}(\mathrm{A})]^{\mathrm{o} \beta} \forall \mathrm{A} \subseteq \mathrm{X}$.

iii) $\left[\mathrm{F}^{-1}(\mathrm{~A})\right]^{\circ} \subseteq \mathrm{F}^{-1}\left(\mathrm{~A}^{\mathrm{o} \beta}\right) \forall \mathrm{A} \subseteq \mathrm{Y}$.

\section{Proof:}

i) ------ ii)

Let $A \subseteq X$. Since $A^{\circ}$ open in $X$, then $F\left(A^{\circ}\right)$ $\beta$ - open in $Y$ by (i). Then $F\left(A^{\circ}\right)=\left[F\left(A^{\circ}\right)\right]^{o \beta} \subseteq$ $[\mathrm{F}(\mathrm{A})]^{\mathrm{o} \beta}$. Hence $\mathrm{F}\left(\mathrm{A}^{\circ}\right) \subseteq[\mathrm{F}(\mathrm{A})]^{\mathrm{o} \beta}$.

ii) ------- (iii)

Let $\mathrm{A} \subseteq \mathrm{Y}$, then $\mathrm{F}^{-1}(\mathrm{~A}) \subseteq \mathrm{X}$, then $\mathrm{F}\left[\left(\mathrm{F}^{-}\right.\right.$ $\left.\left.{ }^{1}\left(\mathrm{~A}^{\circ}\right)\right)^{\mathrm{o}}\right] \subseteq\left[\mathrm{F}\left(\mathrm{F}^{-1}(\mathrm{~A})\right)\right]^{\mathrm{o} \beta}$ by (ii). Then $\mathrm{F}\left[\left(\mathrm{F}^{-1}(\mathrm{~A})\right)^{\circ}\right] \subseteq$ $\mathrm{A}^{\mathrm{o} \beta}$. Then $\left[\mathrm{F}^{-1}(\mathrm{~A})\right]^{\circ} \subseteq \mathrm{F}^{-1}\left(\mathrm{~A}^{\mathrm{o} \beta}\right)$.

iii) ------ (i)

Let $\mathrm{A}$ open in $\mathrm{X}$, then $\mathrm{A}=\mathrm{A}^{\circ}$. Let $\mathrm{F}(\mathrm{A}) \subseteq$ $\mathrm{Y}$, then $\left[\mathrm{F}^{-1}(\mathrm{~F}(\mathrm{~A}))\right]^{\circ} \subseteq \mathrm{F}^{-1}\left[(\mathrm{~F}(\mathrm{~A}))^{\mathrm{o} \beta}\right]$, by (iii). Then $\mathrm{A}=\mathrm{A}^{\circ}$ $\subseteq \mathrm{F}^{-1}\left[(\mathrm{~F}(\mathrm{~A}))^{\mathrm{o} \beta}\right]$, then $\mathrm{F}(\mathrm{A}) \subseteq[\mathrm{F}(\mathrm{A})]^{\mathrm{o} \beta}$. But $[\mathrm{F}(\mathrm{A})]^{\mathrm{o} \beta} \subseteq \mathrm{F}(\mathrm{A})$, then $\mathrm{F}(\mathrm{A})=[\mathrm{F}(\mathrm{A})]^{\mathrm{o} \beta}$. Hence $\mathrm{F}$ (A) $\beta$ - open in $Y$, there fore $F \beta$ - open function.

\section{Proposition (4.11):}

Let $\mathrm{F}: \mathrm{X} \rightarrow \mathrm{Y}$ be function. Then the following statement are equivalent.

i) $\mathrm{F} \mathrm{B}^{*} \mathrm{c}-$ open function.

ii) $\mathrm{F}\left(\mathrm{A}^{\circ}\right) \subseteq[\mathrm{F}(\mathrm{A})]^{\mathrm{o} \mathrm{B}^{*} \mathrm{C}} \forall \mathrm{A} \subseteq \mathrm{X}$.

iii) $\left[\mathrm{F}^{-1}(\mathrm{~A})\right]^{\circ} \subseteq \mathrm{F}^{-1}\left(\mathrm{~A}^{\mathrm{oB}} \mathrm{B}^{*} \mathrm{C}\right) \forall \mathrm{A} \subseteq \mathrm{Y}$.
Proof:

i) ------- ii)

Let $A \subseteq X$. Since $A^{\circ}$ open in $X$, then $F\left(A^{\circ}\right)$ $\mathrm{B}^{*} \mathrm{c}$ - open in $\mathrm{Y}$ by (i). Then $\mathrm{F}\left(\mathrm{A}^{\circ}\right)=\left[\mathrm{F}\left(\mathrm{A}^{\circ}\right)\right]^{0 \mathrm{~B}^{*} \mathrm{C} \subseteq}$ $[\mathrm{F}(\mathrm{A})]^{\mathrm{o} \mathrm{B}^{*} \mathrm{C}}$. Hence $\mathrm{F}\left(\mathrm{A}^{\circ}\right) \subseteq[\mathrm{F}(\mathrm{A})]^{\mathrm{oB} \mathrm{B}^{*} \mathrm{C}}$.

ii) ------ (iii)

Let $\mathrm{A} \subseteq \mathrm{Y}$, then $\mathrm{F}^{-1}(\mathrm{~A}) \subseteq \mathrm{X}$, then $\mathrm{F}\left[\left(\mathrm{F}^{-}\right.\right.$ $\left.\left.{ }^{1}\left(A^{\circ}\right)\right)^{\circ}\right] \subseteq\left[F\left(F^{-1}(A)\right)\right]^{o B^{*} C}$ by (ii). Then $F\left[\left(F^{-1}(A)\right)^{\circ}\right]$ $\subseteq \mathrm{A}^{\mathrm{oB}} \mathrm{B}^{*} \mathrm{C}$, hence $\left[\mathrm{F}^{-1}(\mathrm{~A})\right]^{\circ} \subseteq \mathrm{F}^{-1}\left(\mathrm{~A}^{\mathrm{o} \mathrm{B}^{*} \mathrm{C}}\right)$.

iii) ------ (i)

Let $A$ open in $X$, then $A=A^{\circ}$. Let $F(A) \subseteq$ $\mathrm{Y}$, then

$\left[\mathrm{F}^{-1}(\mathrm{~F}(\mathrm{~A}))\right]^{\circ} \subseteq \mathrm{F}^{-1}\left[(\mathrm{~F}(\mathrm{~A}))^{\mathrm{o} \mathrm{B}^{*} \mathrm{C}}\right]$, by (iii). Then $\mathrm{A}=$ $\mathrm{A}^{\circ} \subseteq \mathrm{F}^{-1}\left[(\mathrm{~F}(\mathrm{~A}))^{\mathrm{o} \mathrm{B}^{*} \mathrm{C}}\right]$, then $\mathrm{F}(\mathrm{A}) \subseteq[\mathrm{F}(\mathrm{A})]^{\mathrm{o} \mathrm{B}^{*} \mathrm{C}}$. But $[\mathrm{F}(\mathrm{A})]^{\mathrm{o} \mathrm{B}^{*} \mathrm{C}} \subseteq \mathrm{F}(\mathrm{A})$, then $\mathrm{F}(\mathrm{A})=[\mathrm{F}(\mathrm{A})]^{\mathrm{o} \mathrm{B}^{*} \mathrm{C}}$. Hence $\mathrm{F}$ (A) BC- open in $\mathrm{Y}$, there fore $\mathrm{F} \mathrm{Bc}$ - open function.

\section{Proposition (4.10):}

A function $F: X \rightarrow Y$ is a $\beta$ - closed iff $\overline{\mathrm{F}(\mathrm{A})}^{\beta} \subseteq \mathrm{F}(\overline{\mathrm{A}}) \forall \mathrm{A} \subseteq \mathrm{X}$.

\section{Proof:}

Suppose $F$ is a $\beta$ - closed. Let $A \subseteq X$, then $\bar{A}$ closed in $X$, then $F(\bar{A})$ is a $\beta$ - closed in $Y$.

Then $\overline{\mathrm{F}(\mathrm{A})}^{\beta} \subseteq \overline{\mathrm{F}(\overline{\mathrm{A}})^{\beta}}=\mathrm{F}(\overline{\mathrm{A}})$.

Conversely

Let $A$ be closed in $X$, then $A=\bar{A}$ Since

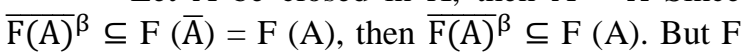
(A) $\subseteq \overline{\mathrm{F}(\mathrm{A})^{\beta}}$, then $\mathrm{F}(\mathrm{A})=\overline{\mathrm{F}(\mathrm{A})}{ }^{\beta}$. There fore $\mathrm{F}(\mathrm{A})$ is a $\beta$ - closed set in Y. Hence $F$ is a $\beta$ - closed.

\section{Proposition (4.11):}

A function $\mathrm{F}: \mathrm{X} \rightarrow \mathrm{Y}$ is a $\mathrm{B}^{*} \mathrm{c}$ - closed iff $\overline{\mathrm{F}(\mathrm{A})}{ }^{\mathrm{B}^{*} c} \subseteq \mathrm{F}(\overline{\mathrm{A}}) \forall \mathrm{A} \subseteq \mathrm{X}$.

Proof:

Suppose that $\mathrm{F}$ is a $\mathrm{B}^{*} \mathrm{c}$ - closed.

Let $A \subseteq X$, then $\bar{A}$ closed set in $X$, then $F(\bar{A})$ is a $\mathrm{B}^{*} \mathrm{c}$ - closed in $\mathrm{Y}$.

Then $\overline{\mathrm{F}(\mathrm{A})} \mathrm{B}^{*} \mathrm{C} \subseteq \overline{\mathrm{F}(\overline{\mathrm{A}})}{ }^{\mathrm{B}^{*} \mathrm{C}}=\mathrm{F}(\overline{\mathrm{A}})$.

Conversely

Let $A$ be closed in $X$, then $A=\bar{A}$ Since $\overline{\mathrm{F}(\mathrm{A})}{ }^{\mathrm{B}^{*} \mathrm{C}} \subseteq \mathrm{F}(\overline{\mathrm{A}})=\mathrm{F}(\mathrm{A})$, then $\overline{\mathrm{F}(\mathrm{A})} \mathrm{B}^{\mathrm{B}^{*} \mathrm{C}} \subseteq \mathrm{F}(\mathrm{A})$. But $\mathrm{F}(\mathrm{A}) \subseteq \overline{\mathrm{F}(\mathrm{A})}{ }^{\mathrm{B}^{*} \mathrm{C}}$, then $\mathrm{F}(\mathrm{A})=\overline{\mathrm{F}(\mathrm{A})} \mathrm{B}^{*} \mathrm{C}$. There fore $\mathrm{F}(\mathrm{A})$ is a $\mathrm{B}^{*} \mathrm{c}$ - closed set in $\mathrm{Y}$. Hence $\mathrm{F}$ is a $\mathrm{B}^{*} \mathrm{c}$ closed. 


\section{References}

[1] Abd El - Monsef M. E., El - Deeb S. N. Mahmoud R. A., " $\beta$ - open sets and $\beta$ - continuous function" Bulletin of the Faculte of science, Assiut university, 12, pp. $77-90,1983$.

[2] L.A. Steen and J.A. Seebach, "Counter Examples in Topology" Springer - Verlag, New York Inc. , 1978.
[3] W. J. Pervin, "Foundation Of General Topology" Academic Press, New York, 1964.

[4] Najastad O (1965) " On Some Classes Of Nearly Open Sets". Pacific J Math 15 : 961 - 970.

[5] Andijevic D (1986) Semipre Open Sets. Math. Vesink 38:24 - 32.

[6] Ryszard Engelking General Topology 1988.

\title{
حول خصائص المجموعة B* open set

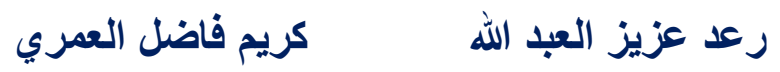 \\ جامعة القادسية \\ كلية علوم الحاسوب وتكنلوجيا المعلومات
}

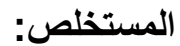

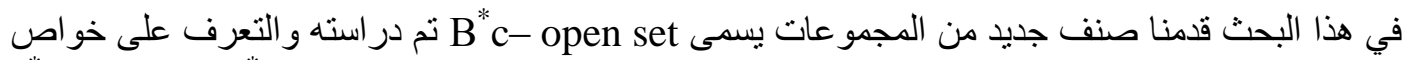

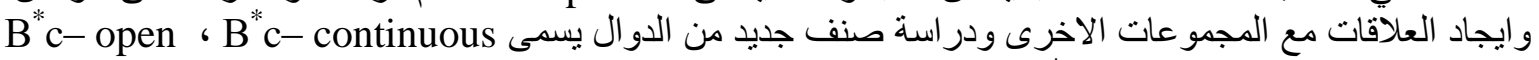

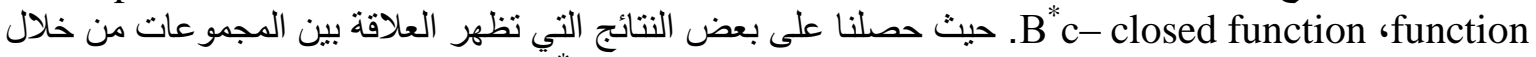

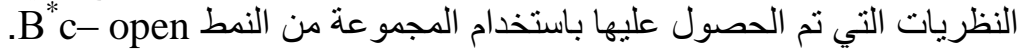

